\title{
PERANCANGAN GAME BUDAYAKU INDONESIAKU MENGGUNAKAN METODE MDLC
}

\author{
Dian Nurdiana $^{1}$, Andri Suryadi ${ }^{2}$ \\ Program StudiPendidikan Teknologi Informasi, Fakultas Ilmu Terapan dan Sains \\ Institut Pendidikan Indonesia \\ 11. \\ 2andrisuryadi@institutpendidikan.ac.id
}

\begin{abstract}
Penggunaan game telah menjadi bagian dalam kehidupan sehari-hari. Di Indonesia ,Sebagai sebuah media, game sendiri telah menciptakan gaya belajar yang baru. Game edukasi selalu dikembangkan berdasarkan kurikulum yang dikemas dalam tema game itu sendiri. Game saat ini sangat diminati oleh berbagai kalangan khususnya anak-anak. Ketertarikan anak-anak pada game dapat dijadikan sebagai sarana edukatif untuk peningkatan kemampuan anak-anak contohnya dibidang. Budayaku Indonesiaku dikembangkan dengan media flash bertujuan menguji keterampilan dalam bentuk game edukasi. Game ini ditujukan untuk jenjang TK sampai dengan SD. Untuk meningkatkan minat anak dalam bermain, maka ditambahkan fitur artificial intelligence (AI) didalam game. Penerapan artificial intelligence diharapkan dapat menambah kesenangan bermain dan menambah variasi pada game.

Kata Kunci : Game edukasi, AI, flash ,game budayaku Indonesia ,photoshop
\end{abstract}

\section{PENDAHULUAN}

Saat ini berbagai media telah digunakan dan dikembangkan untuk kebutuhan pembelajaran. Proses inovasi tersebut juga merambah di bidang teknologi informasi. Salah satu teknologi informasi yang dapat digunakan untuk kepentingan itu adalah media game komputer. Game didefinisikan sebagai salah satu tipe aktifitas bermain, di mana terdapat pemain, dan pemain berusaha untuk memenuhi tujuan sesuai dengan peraturan yang telah dirancang.

Seiring dengan perkembangan jaman, game dapat diintegrasikan dengan unsur-unsur psikologi atau logika seperti halnya manusia. Artificial Intelligent (AI) atau kecerdasan buatan merupakan bagian ilmu komputer yang membuat mesin (komputer) memiliki kemampuan seperti itu. Bagian utama yang membuat sebuah perangkat memiliki kemampuan kecerdasan buatan disebut sebagai agen cerdas. Russel dan Norvig mengatakan bahwa, AI adalah kreasi program komputer yang memiliki aksi dan pemikiran seperti manusia. Definisi ini meliputi kecerdasan dari sudut pandang perilaku dan kognitif termasuk logika dan perasaan.

Game menjadi salah satu pilihan untuk pembelajaran bagi anak-anak. Pembelajaran menggunakan game merupakan salah satu model yang dirasa efektif karena membuat pemain berlama-lama dalam bermain, walaupun tanpa sadar mereka sebenarnya adalah sedang belajar. Salah satu game yang kami rancang yaitu game buadayaku indonesiaku yang sifatnya mendidik akan membantu anak-anak memahami apa yang diajarkan. Game ini mengenalkan keterampilan anak-anak melalui objek-objek berupa hewan yang ada dilingkungan sekitar. Game akan dikembangkan menggunakan software flash.

\section{LANDASAN TEORI \\ 2.1 Game Edukasi \\ 2.1.1 Pengertian Game}

(Ghea Putri Fatma Dewi: 2012) Game adalah kata berbahasa Inggris yang berarti permainan atau pertandingan, atau bisa diartikan sebagai aktifitas terstruktur yang biasanya dilakukan untuk bersenang-senang. Game atau permainan adalah sesuatu yang dapat dimainkan dengan aturan tertentu sehingga ada yang menang dan ada yang kalah, biasanya dalam konteks tidak serius dengan tujuan refreshing. Macam-macam game diantaranya; aksi, aksi petualangan, simulasi, konstruksi, dan manajemen, role playing games (RPG), strategi, balapan, olahraga, puzzle, dan permainan kata.

\subsubsection{Pengertian Edukasi}

Dalam kamus besar bahasa Inggris education berarti pendidikan, sedangkan menurut Sugihartono, 2007 (Ghea Putri Fatma Dewi: 2012) pendidikan berasal dari kata didik, atau mendidik yang berarti memelihara dan membentuk latihan. Sedangkan dalam Kamus Besar Bahasa Indonesia (1991) pendidikan diartikan sebagai proses pengubahan sikap dan tata laku seseorang atau sekelompok orang dalam usaha mendewasakan manusia melalui upaya pengajaran dan pelatihan. 
Pendidikan adalah sebuah proses pembelajaran yang didapat oleh setiap manusia, dalam hal ini adalah peserta didik, tujuannya adalah untuk membuat peserta didik itu paham, mengerti serta mampu berpikir lebih kritis. Pendidikan dapat dirumuskan sebagai tuntunan pertumbuhan manusia sejak lahir hingga tercapai kedewasaan jasmani dan rohani, dalam interaksi alam dan lingkungan masyarakatnya. Pendidikan merupakan proses yang terus menerus, tidak berhenti.

Pendidikan dapat didapat secara formal maupun non formal. Pendidikan formal diperoleh dari suatu pembelajaran yang terstruktur yang telah dirancang oleh suatu institusi. Sedangkan pendidikan non formal adalah pengetahuan yang didapat manusia dalam kehidupan sehari-hari baik yang dialami atau yang dipelajari dari orang lain.

(Ghea Putri Fatma Dewi: 2012) Edukasi adalah suatu usaha sadar dan secara terus menerus yang dilakukan pemerintah, keluarga, dan masyarakat untuk tujuan mengubah suatu individu menjadi berarah dan lebih baik dalam segala aspek kehidupannya.

\subsubsection{Pengertian Game Edukasi}

Game edukasi adalah permaian yang dirancang atau dibuat untuk merangsang daya pikir termasuk meningkatkan konsentrasi dan memecahkan masalah Handriyantini, 2009 (Ghea Putri Fatma Dewi: 2012).

Game Edukasi adalah salah satu jenis media yang digunakan untuk memberikan pengajaran, menambah pengetahuan penggunanya melalui suatu media unik dan menarik. Jenis ini biasanya ditujukan untuk anak- anak, maka permainan warna sangat diperlukan disini bukan tingkat kesulitan yang dipentingkan.

(Ghea Putri Fatma Dewi: 2012) Game edukasi adalah salah satu bentuk game yang dapat berguna untuk menunjang proses belajar-mengajar secara lebih menyenangkan dan lebih kreatif, digunakan untuk memberikan pengajaran atau menambah pengetahuan penggunanya melalui suatu media yang menarik.

\subsection{Kecerdasan Buatan (Artificial Inttelegence)}

(Muhammad Dahria, 2008: vol. 5, no. 2, p. 185) Kecerdasan Buatan (Artificial Inttelegence) merupakan salah satu bagian dari ilmu komputer yang mempelajari bagaimana membuat mesin (komputer) dapat melakukan pekerjaan seperti dan sebaik yang dilakukan oleh manusia bahkan bisa lebih baik dari pada yang dilakukan manusia.

Menurut John McCarthy, 1956 (Muhammad Dahria, 2008: vol. 5, no. 2, p. 185) AI: untuk mengetahui dan memodelkan proses-proses berpikir manusia dan mendesain mesin agar dapat menirukan perilaku manusia. Cerdas, berarti memiliki pengetahuan ditambah pengalaman, penalaran (bagaimana membuat keputusan dan mengambil tindakan), moral yang baik.
(Rizal, 2015: vol. 6, no. 1, p. 173) Kecerdasan buatan adalah sebuah studi ilmu yang mengupayakan supaya mesin (komputer) bertindak secara cerdas dan mampu menyelesaikan persoalan yang sulit dan dapat melakukan pekerjaan seperti yang dapat dilakukan oleh manusia.

(Muhammad Dahria, 2008: vol. 5, no. 2, p. 185) Agar mesin bisa cerdas (bertindak seperti dan sebaik manusia) maka harus diberi bekal pengetahuan, sehingga mempunyai kemampuan untuk menalar. Untuk membuat aplikasi kecerdasan buatan ada 2 bagian utama yang sangat dibutuhkan:

1) Basis Pengetahuan (Knowledge Base), bersifat fakta-fakta, teori, pemikiran dan hubungan antar satu dengan yang lainnya.

2) Motor Inferensi (Inference Engine), kemampuan menarik kesimpulan berdasarkan pengetahuan dan pengalaman.

(Muhammad Dahria, 2008: vol. 5, no. 2, p. 185) Penerapan konsep kecerdasan buatan pada komputer adalah sebagai berikut:

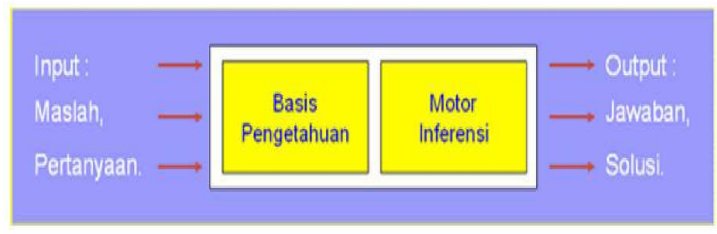

Gambar 2.1 Penerapan Konsep Kecerdasan Buatan di Komputer

\subsection{Adobe FLASH CS3}

Flash adalah program yang dapat membuat suatu animasi(animation) gambar yang bisa bergerak. Program ini hanya bisa membuat dasar atau juga bisa membuat aplikasi game dasar. Flash ini mempunyai yang namanya motion tween dan action script.

merupakan salah satu software bagian dari keluarga Adobe, yang sekarang menjadi salah satu standar untuk industri animasi dan web yang banyak digunakan.

Perangkat lunak "Adobe Flash" yang selanjutnya disebut Flash dulunya bernama "Macromedia Flash" adalah software multimedia unggulan yang dulunya dikembangkan oleh Macromedia, tetapi sekarang dikembangkan dan didistribusikan oleh "Adobe System". Sejak tahun 1996, Flash menjadi metode populer untuk menambahkan animasi dan interaktif web site.

Flash biasanya digunakan untuk membuat animasi, hiburan dan berbagai komponen web, diintegrasikan dengan video dalam halaman web sehingga dapat menjadi aplikasi multimedia yang kaya (Rich Internet Application). Flash tidak hanya digunakan untuk aplikasi Web, tetapi dapat juga dikembangkan untuk membangun 
aplikasi desktop karena aplikasi Flash selain dapat menjadi format .swf, Flash juga dapat dapat menjadi format .exe.

\subsection{PHOTOSHOP}

Photoshop adalah software yang digunakan untuk memodifikasi gambar atau foto secara profesional baik meliputi modifikasi obyek yang sederhana maupun yang sulit sekalipun. Photoshop merupakan salah satu software yang berguna untuk mengolah gambar berbasis bitmap, yang mempunyai tool dan efek yang lengkap sehingga dapat menghasilkan gambar atau foto yang berkwalitas tinggi (jika ingin lebih jauh mengetahui tentang gambar berbasis bitmap silakan download dokumennya di sini).Kelengkapan fitur yang ada di dalam Photoshop inilah yang akhirnya membuat software ini banyak digunakan oleh desainer grafis profesional. Dan mungkin juga sampai saat ini masih belum ada software desain grafis lain yang bisa menyamai kelengkapan fitur dalam Photoshop.

\section{PERANCANGAN SISTEM DAN IMPLEMENTASI 3.1 Perancangan Game \\ 3.1.1 Konsep Permainan}

Game edukasi yang kami bangun berupa game dengan model "Edukasi Search Button". Bentuk permainannya adalah pemain disediakan gambar dari Peta Indonesia yang mengharuskan pemain untuk memilih provinsi yang ingin diketahui budayanya, setelah dipilih oleh pemain maka pemain akan diarahkan pada gambar kota dari provinsi tersebut beserta ikonnya. Namun pemain harus mencari terlebih dahulu button (tombol) untuk mengetahui budaya dari provinsi tersebut, setelah pemain menemukan button (tombol) tersebut maka pemain dapat mengetahui dan mempelajari budaya provinsi tersebut.

Game ini masih bersifat beta version (versi beta) yang masih memerlukan pengembangan, terutama pada daerah provinsi yang masih menyertakan 5 Provinsi d setiap pulau yang ada di Indonesia.

\subsubsection{Identifikasi Kebutuhan dan Analisis Sistem}

Identifikasi kebutuhan dan analisis sistem merupakan proses mengidentifikasi semua kegiatan yang dilakukan oleh setiap pihak dalam proses bisnis. Dari sistem game edukasi yang akan dibangun, kami mendefinisikan identifikasi kebutuhan dan analisis sistem sebagai berikut:

1) Kebutuhan Fungsional

a) Sistem dapat menyajikan gambar-gambar ibu kota provinsi yang ada di Indonesia.

b) Sistem dapat menampilkan buadaya dari setiap Provinsi yang ada di Indonesia

c) Sistem dapat menyajikan informasi tentang game dan pengembang game.

\section{2) Kebutuhan Non-Fungsional}

Dari sistem yang dibangun maka didefinisikan bentuk kebutuhan non-fungional sebagai berikut:

a) Performa: Memiliki respon yang cepat

b) Informasi: Informasi yang ditampilkan sesuai

c) Kontrol: Kontrol sistem harus mudah digunakan

d) Efisiensi: Sistem berjalan lancar

e) Servis: Sistem harus mudah digunakan

\subsubsection{Kebutuhan Perangkat Lunak dan Perangkat Keras}

Dibawah ini akan dijabarkan spesifikasi perangkat lunak dan spesifikasi perangkat keras untuk memainkan game Budayaku Indonesiaku sebagai berikut:

\section{1) Sistem Perangkat Lunak}

Sistem perangkat lunak yang digunakan untuk merancang aplikasi ini adalah sebagai berikut:

a) Sistem operasi windows $\mathrm{XP}$, windows 7 , windows 8 , atau windows 10

b) Program aplikasi utama dalam perancangan menggunakan program flash

2) Sistem Perangkat Keras

Secara umum, aplikasi yang dibangun tidak memiliki spesifikasi khusus agar dapat dijalankan oleh pengguna karena sangat ringan. Namun dianjurkan memenuhi spesifikasi minimal perangkat keras yang dibutuhkan sebagai berikut:
a) Processor : Pentium IV
b) $R A M: 512 M B$
c) Harddisk : 2 GB free space
d) VGA Card : on board
e) Sound Card: on board
f) Mouse, keyboard, speaker, monitor

\subsubsection{Tahap Pengembangan Sistem}

Sesuai referensi dari Jurnal Teknologi dan Sistem Komputer Metodologi yang digunakan dalam pengembangan game ini adalah Multimedia Development Life Cycle (MDLC) yang bersumber dari Luther dan sudah dimodifikasi oleh Sutopo. Metodologi pengembangan multimedia tersebut terdiri dari enam tahap, yaitu konsep (concept), desain (design), pengumpulan materi (material collecting), pembuatan (assembly), pengujian (testing), dan distribusi (distribution). Keenam tahap ini tidak harus berurutan dalam prakteknya, tahap-tahap tersebut dapat saling bertukar posisi. Metodologi pengembangan multimedia Luther yang telah dimodifikasi oleh Sutopo ini dapat dilihat pada gambar dibawah ini: 


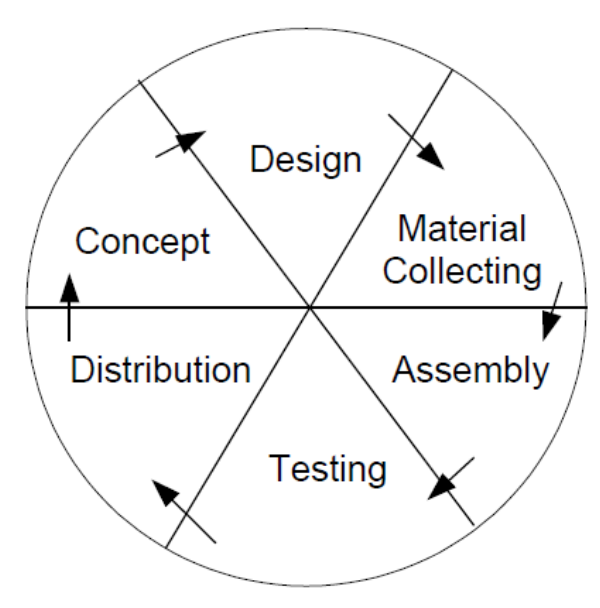

Gambar 3.1 Tahap pengembangan multimedia menurut Luther yang sudah dimodifikasi oleh Sutopo

\subsubsection{Konsep Dasar Pembangunan Game}

Setelah merancang alur permainan yang diinginkan langkah berikutnya adalah menterjemahkannya menjadi konsep dasar pembangunan game. Konsep dasar pembangunan game berupa dua buah loop yang saling berinteraksi antara sistem game dengan agen cerdas.

\subsubsection{Perancangan Diagram Alir (Flowchart)}

Konsep dasar pembangunan game yang telah dibuat selanjutnya menjadi acuan dalam merancang diagram alir (flowchart) seperti tampak pada gambar berikut ini.

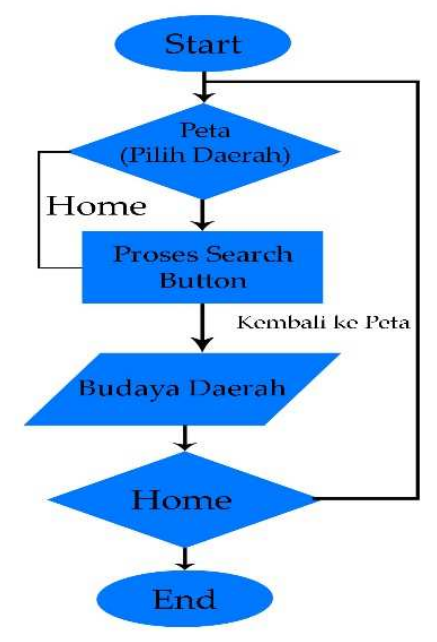

Gambar 3.3 Flowchart Game Budayaku Indonesiaku

\subsubsection{Perancangan Antarmuka}

Fungsi antarmuka adalah menterjemahkan isi skenario secara visual atau penggambaran secara singkat bentuk karya multimedia. Antarmuka game ini tampak pada gambar di bawah.

1. Membuat halaman awal

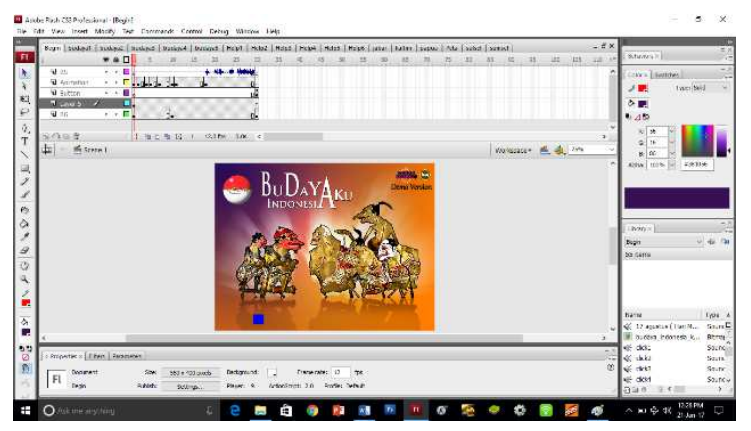

Gambar 3.4 halaman awal

2. Memasukan gambar untuk background games

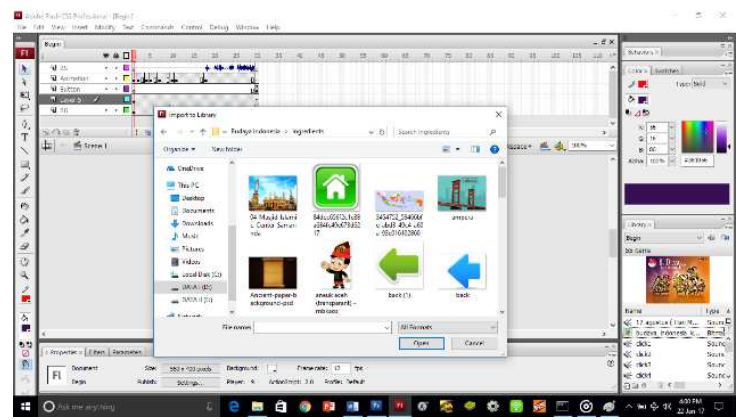

Gambar 3.5 background games

3. Membuat tampilan game

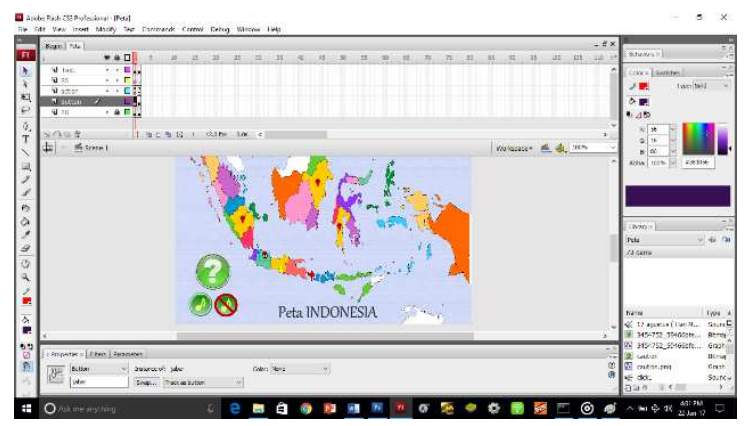

Gambar 3.6 tampilan game 
4. Tampilan games

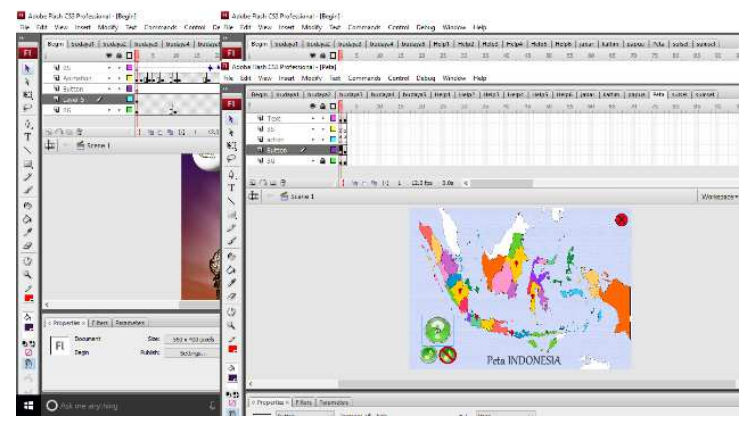

Gambar 3.7 Tampilan games

1. Actionscript

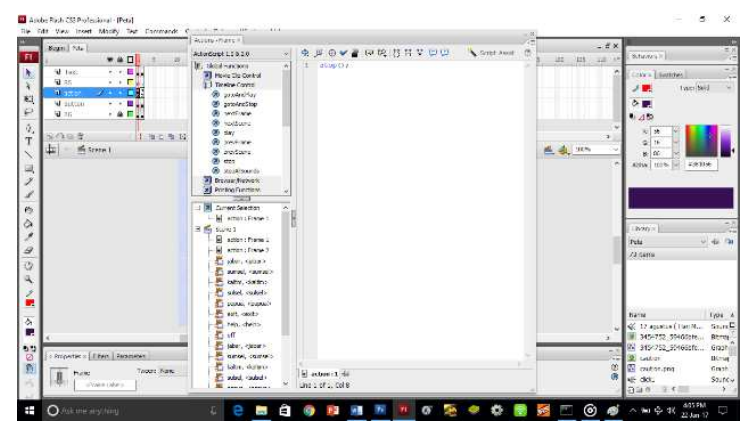

Gambar 3.8 Actionscript

2. Actionscript Sound

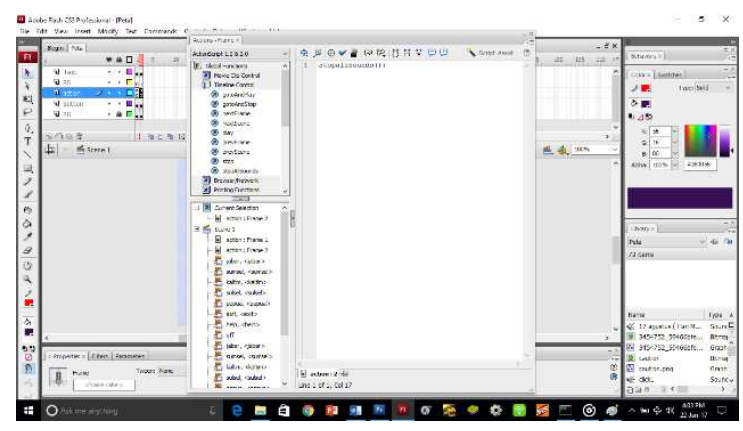

Gambar 3.9 Actionscript sound

3. Halaman Awal (Loading)

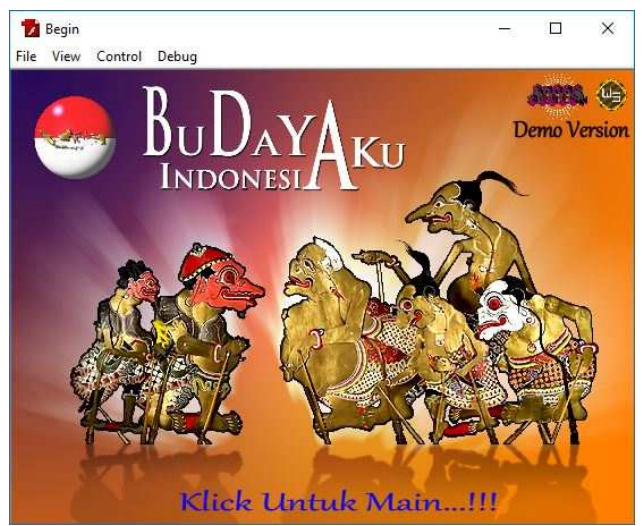

Gambar 3.10 Halaman Awal

4. Halaman Utama permainan

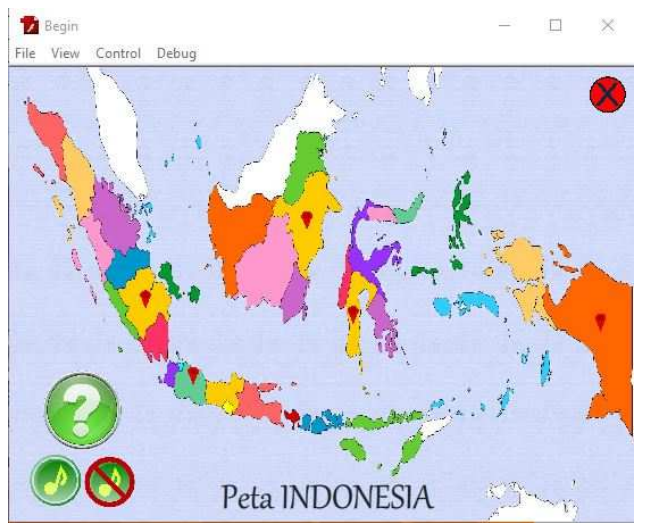

Gambar 3.11 Halaman Utama permainan

5. Tampilan Search Button (Mencari Button Tersembunyi)

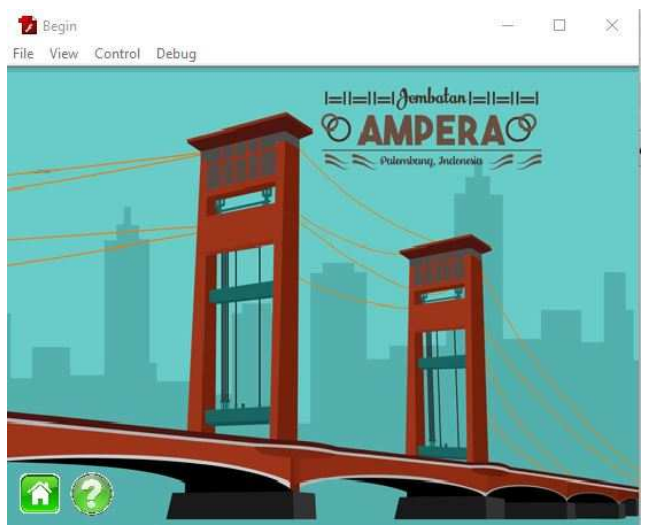

Gambar 3.12Halaman Search

6. Jika Button berhasil ditemukan dan di klik 


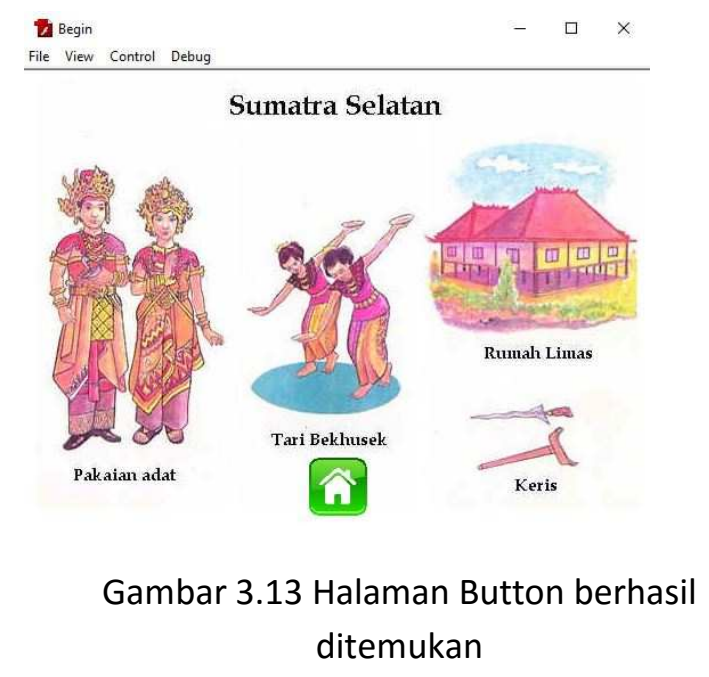

\subsection{Hasil dan Pembahasan}

Permainan Mencari tombol budaya (Search Button) yang akan dibangun ini hanya dimainkan oleh satu pihak. Pemain adalah pencari tombol budaya dan yang ingin mengetahui budaya daerahyang ada di Indonesia yang disediakan oleh komputer itu sendiri yang mana sudah ditanamkan kecerdasan buatan di dalamnya untuk melengkapi atau mencari budaya yang ingin diketahui atau dipelajari oleh pemain.

Pemain dapat memainkan permainan tersebut dtanpa batas waktu yang di tentukan,. Setiap gambar memiliki gambargambar budaya daerah dan ikon dari daerah tersebut sehingga pemain selain mengetahui budaya daerah juga dapat mengetahui gambar dan ikon daerah tersebut

\section{.KESIMPULAN DAN SARAN}

\subsection{Kesimpulan}

Kecerdasan Buatan (AI) merupakan suatu sistem yang pada umumnya merupakan suatu mesin (komputer) agar dapat melakukan pekerjaan seperti yang dapat dilakukan manusia. Ada beberapa macam bidang menggunakan kecerdasan buatan salah satunya dalah permainan komputer (games). Game Playing (permainan) merupakan bidang AI yang sangat populer berupa permainan antara manusia melawan mesin yang mempunyai intelektual untuk berpikir. Dalam hal ini kelompok kami telah merencanakan dan mengembangkan education games (Game Edukasi) untuk penguasaan mencari tombol budaya (Search Button) gambar budaya dan ikon daerah. Game tersebut dibuat dengan menggunakan tool utama pada adobe flash CS3 dan grafik dari adobe Photoshop CS3.

\section{IV.DAFTAR PUSTAKA}

[1].Setyosari, Punaji. 2010. Pemanfaatan Media. Malang:Universitas Negeri Malang

[2].Krishna Murti, Tendi dkk. 2012. 50 Permainan Edukatif Untuk Mengembangkan Potensi dan Mental Positif. Yogyakarta: PT. Citra Aji Parama.

[3].Muhammad D. (2008). "Kecerdasan Buatan (Artificial Intelligence)". Jurnal SAINTIKOM. 5(2), 185-186.

[4]. Rahayu, Gina. Suryadi, Andri.(2017). GAME ARTIFICIAL INTELEGENT: RAM CITY TOWER DENGAN ALGORITMA A. Jurnal PETIK Vol.3 No.2 2017 Hal 31-38

[5] Suryadi. Andri.(2017). PERANCANGAN APLIKASI GAME EDUKASI MENGGUNAKAN MODEL WATERFALL. Jurnal PETIK Vol.3 No.1 2017 Hal 8-13 